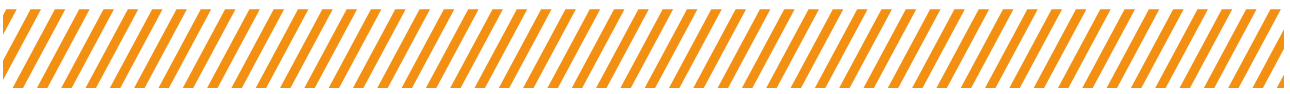

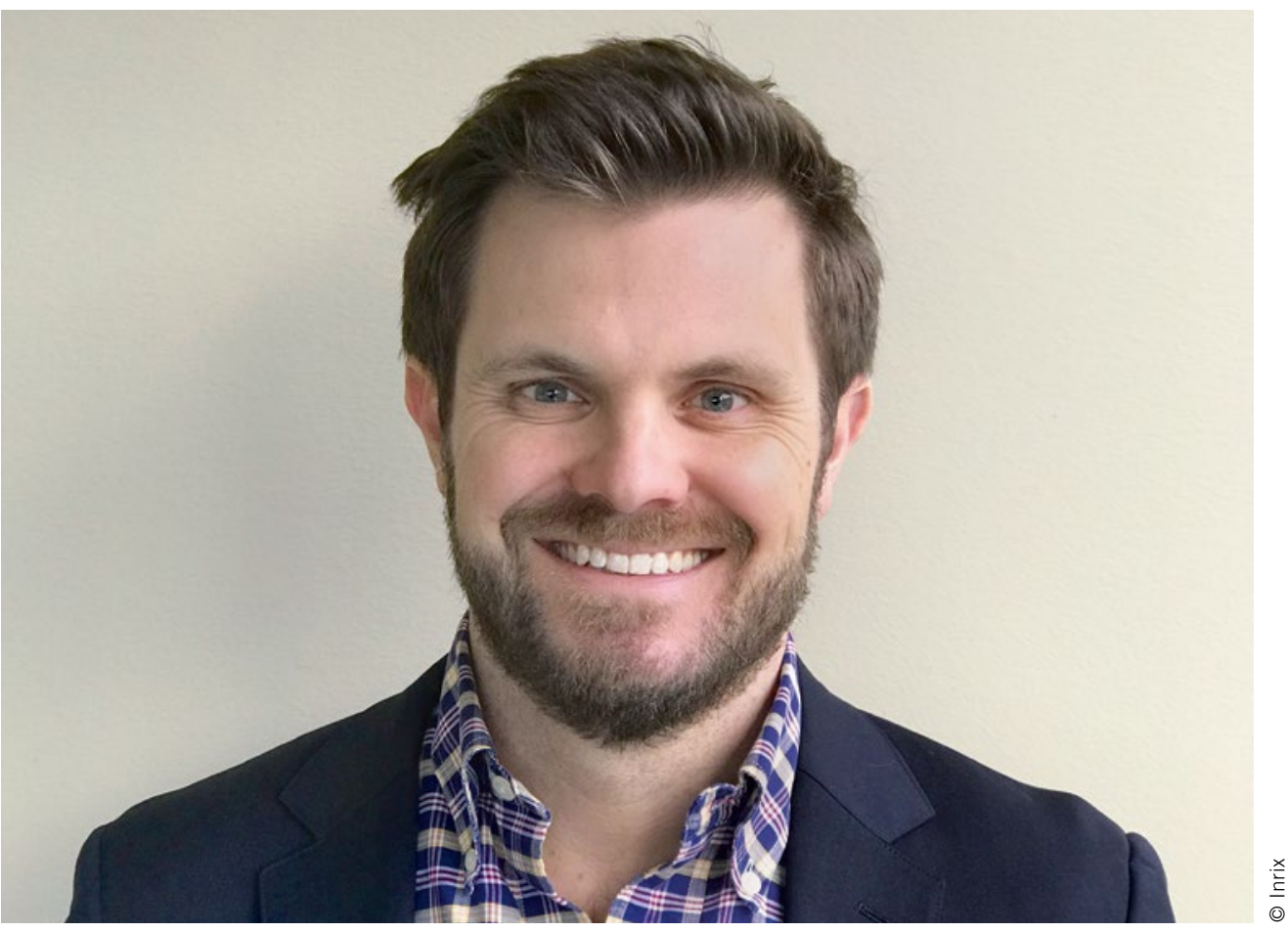

Avery Ash

ist Autonomous Vehicle Market Strategist bei Inrix in Washington DC (USA)

\section{Ingenieure müssen aufklären}

Die Menschen stehen tiefgreifenden technologischen Veränderungen in vielen Bereichen ihres Alltags gegenüber - bei der Arbeit, in der Freizeit und immer stärker auch bei Fragen der Mobilität. Elektromobilität, vernetztes und autonomes Fahren rücken immer mehr ins Zentrum des Interesses und versprechen eine sicherere, bequemere und effizientere Zukunft. Trotzdem zeigen Studien, dass die Öffentlichkeit noch skeptisch gegenüber der Sicherheit und Leistungsfähigkeit selbstfahrender Fahrzeuge ist. Diese Skepsis basiert nicht auf Fehlern der Technik an sich, denn Studienteilnehmer, die bereits Fahrerassistenzsysteme nutzen, vertrauen ihnen schnell. Das Misstrauen basiert eher auf falschen Informationen, fehlendem Verständnis für die Technik und generellen Vorbehalten, die Kontrolle an Maschinen zu übergeben.

Experten der Autoindustrie müssen eine zentrale Rolle spielen, um das Vertrauen in das Potenzial und die Leistungsfähigkeit neuer Techniken zu stärken, aber auch deren Grenzen aufzuzeigen. Wesentliche Faktoren des Fortschritts sind die Nutzung von Daten und die Schaffung von Transparenz, durch die sich Wissenschaftler, politische Entscheidungsträger und Verbraucher von den Möglichkeiten der neuen Fahrzeuggeneration überzeugen können. Wir müssen Städte und staatliche Akteure darin bestärken, dass sie ihre Mobilitätsplanung durch datengetriebene Methoden unterstützen. Dabei ist es wichtig, dass neben Marketing- und Kommunikationsverantwortlichen auch
Ingenieure und Techniker als Experten zur Verfügung stehen, um die Technologie glaub- und vertrauenswürdig darzustellen.

Auch wenn es anfangs schwierig ist, komplexe Technologien und die damit verbundenen Veränderungen zu kommunizieren, vereinfacht eine Tatsache diese Aufgabe: Wir haben viele gute Argumente auf unserer Seite. Zum Beispiel können wir schon heute mithilfe von Big Data und der Cloud verbesserte, auf Echtzeitinformationen basierende Sicherheitsfunktionen bieten, wie etwa die Warnung vor Glatteis und Nebel. Mithilfe präziser Daten aus den Navigationssystemen zeigen die HeadUnits vernetzter Fahrzeuge und Smartphones den Autofahrern die schnellsten Fahrrouten an und beziehen dabei die aktuelle Verkehrslage mit ein. Die meisten Menschen nutzen ihre Navigationsgeräte regelmäßig, aber auf täglichen Fahrten wie etwa beim Pendeln kommen sie nur selten zum Einsatz. Denn viele Fahrer sind der Meinung, auf bekannten Wegen keine Navigationsunterstützung zu benötigen, so das Ergebnis einer aktuellen Studie von Inrix. Dennoch wird die Verwendung von Navigationshilfen immer wichtiger werden, um den Verkehr optimal zu leiten und Staustrecken zu entlasten. Automobilhersteller und Betreiber (teil-)autonomer Fahrzeuge sollten daher ihre Ingenieure und Daten-Analysten ermuntern, ihr berufliches und privates Umfeld über die Chancen der Technologie aufzuklären und so die Gestaltung der Mobilität der Zukunft selbst in die Hand zu nehmen. 